\title{
Bioaccumulation of Rare Earth Element by Water Lettuce (Pistia stratiotes)
}

\author{
M. N. M. NAZREEN ${ }^{1}$, A. N. AMALINA ${ }^{2}$ and M. N. OMAR ${ }^{*}$ \\ ${ }^{1}$ Kulliyyah of Allied Health Sciences, International Islamic University Malaysia (IIUM) \\ Bandar Indera Mahkota, 25200 Kuantan Pahang Malaysia. \\ ${ }^{2}$ Kulliyyah of Science, International Islamic University Malaysia (IIUM) \\ Bandar Indera Mahkota, 25200 Kuantan Pahang Malaysia. \\ ${ }^{*}$ Corresponding author E-mail: mnoromar@iium.edu.my \\ http://dx.doi.org/10.13005/ojc/330305
}

(Received: November 12, 2016; Accepted: February 06, 2017)

\begin{abstract}
Processing of rare earth elements produces environmental wastewater pollution containing toxic contaminants. However, these pollutants could be monitored through bioaccumulation using aquatic plant, Pistia stratiotes. Thus, the present research aims to determine the effectiveness of $P$. stratiotes in the bioaccumulation of rare earth metals through phytoremediation. The study was carried out by subjecting the plant to 5 levels of lanthanum chloride treatment for 7 days. The plant samples (root and leaf sections) were digested prior to metal accumulation analysis using Inductively Coupled Plasma-Mass Spectrometry (ICP-MS). The results from the analysis showed that lanthanum accumulated in both the root and leaf sections of $P$. stratiotes. The highest concentration of lanthanum was found in the root section $\left(0.272 \mu \mathrm{g} \mathrm{kg}^{-1}\right)$ on the $2^{\text {nd }}$ day compared to the leaf section $(0.0124 \mu \mathrm{g}$ $\mathrm{kg}^{-1}$ ) on the $6^{\text {th }}$ day, when both parts were treated with $1.0 \mathrm{ppm}$. The study indicates that this aquatic plant can be used to remediate environmental wastewater from REE contamination because of its bioaccumulation capability.
\end{abstract}

Keywords: Bioaccumulation, rare earth element, lantanum, Pistia stratiotes.

\section{INTRODUCTION}

Rare earths are a series of chemical elements found in the earth's crust that are vital to many modem technologies, including consumer electronics, computers, communications and clean energy ${ }^{1}$. Rare earths are also included in the manufacturing of satellite and other communication means for national defense applications ${ }^{2}$. They are also known as rare earth elements (REEs) with unique elements grouped in the periodic table known as the lanthanides series from lanthanum to lutetium, scandium and yttrium ${ }^{3}$.

The wide application of REEs means that demand is growing and will be crucial to the country's economic sector. Due to the importance of the REE industry towards realization of the country's 'Vision 2020' aspirations to become an advanced nation, Malaysia has set up an REE refining plant named 
Lynas Advance Materials Plant (LAMP) in 2009 near Kuantan, Pahang which was issued a 2-year Full Operating Stage Licence (FOSL) in September 2014 by the Atomic Energy Licensing Board (AELB) under the Ministry of Science, Technology and Innovation (MOSTI) ${ }^{4}$. However, during the production and refining of REEs, environmental contamination is caused in the form of release of REE wastewater containing radioactive uranium and thorium ${ }^{5}$. As REEs also include metals, once they enter the environment, they are difficult to destroy but can be transformed into other forms ${ }^{3}$. After entering the environment, these harmful substances have a tendency to be accumulated by plants and animals ${ }^{6}$. Under the temporary operating license (TOL) issued by AELB (MOSTI) in September 2012, Lynas agreed to remove the wastewater residue out of Malaysia ${ }^{7}$. However, the transportation cost of removing the residue out of Malaysia is very expensive.
Phytoremediation through bioaccumulation of rare earth elements containing radioactive contaminants is an environment-friendly solution to the wastewater pollution problem ${ }^{8-11}$. The use of metal-accumulating plants to clean soil and water contaminated with toxic radioactive metals is the most rapidly developing component of phytoremediation. Phytoremediation via bioaccumulation involves the accumulation of substances or chemicals such as heavy metals and rare earth metals by plants ${ }^{12}$. Plants use these rare earth metals to increase crop yields and stimulate chlorophyll synthesis ${ }^{13,14}$. These capabilities prove that plants are able to take up rare earth elements into their various parts. Plants that reside near abandoned mining sites show an ability to accumulate toxic metals and metalloids. Aquatic plants have been explored for several decades as a possible solution to the foregoing environmental, energy and food shortage problems. Several aquatic plants have been evaluated for their potential as a

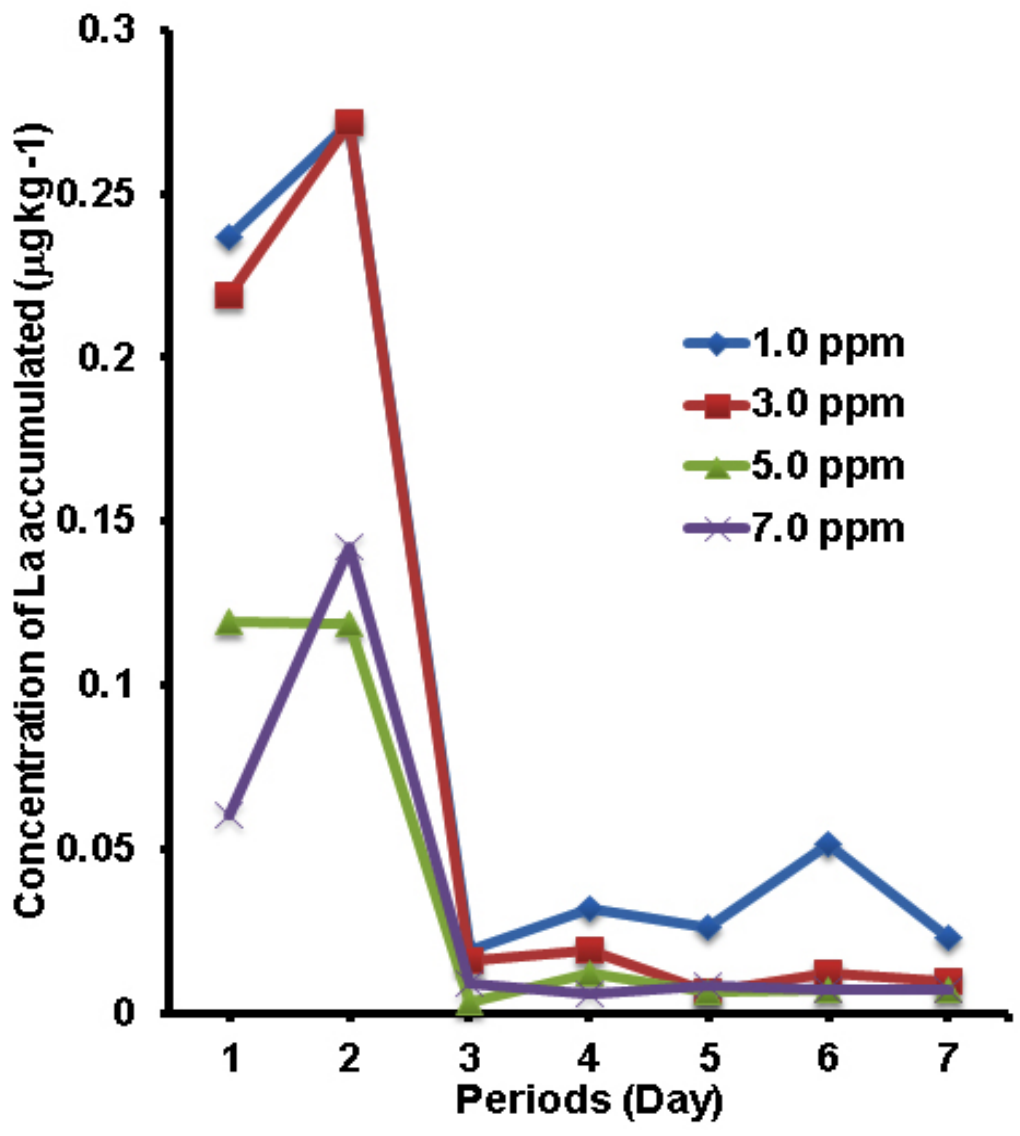

Fig. 1: Concentration of La accumulated by root section of P. stratiotes for all treatments 
biological method to remove heavy metals through bioaccumulation (phytoremediation). For example, Singh et al. ${ }^{12}$ found that several aquatic plants such as P. stratiotes, E. crassipes and Hydrila verticillata could be employed to cleanup lead $(\mathrm{Pb})$ in wastewater. Meanwhile, Razak et al. ${ }^{8}$ used Pistia stratiotes (water lettuce), Eichornia crassipes (water hyacinth) and Salvinia molesta (Giant salvinia) to treat industrial wastewater near the Gebeng area in Pahang. Studies on the treatment of REE wastewater containing radioactive residues using aquatic plants are very limited. However, vegetables, such as Chinese white cabbage (Brassica pekinensis), water spinach (Ipomoea aquatica), lettuce (Lactuca sativa) and eggplant (Solanum melongena) grown in a REE mining area in Southeast China showed high levels of rare earth elements and may pose high health risks when consumed by humans, making them unsuitable for consumption ${ }^{15}$.
The present study aims to determine the effectiveness of aquatic plants in the bioaccumulation of rare earth metals. Successful use of aquatic plants in removing toxic REEs will become a new benchmark for innovation not only in Malaysia but worldwide. It will also support the Malaysian Government Policy through the implementation of the 11th Malaysia Plan (2016-2020 - Anchoring Growth on People) under Strategy B5 (Managing Waste Holistically) to ensure a safe and clean environment for our future generation ${ }^{16}$.

\section{MATERIALS AND METHOD}

\section{Aquatic Plant}

Pistia stratiotes sample was obtained from local nurseries in Kuantan. The plant was cultivated in an aquaponics system at Kulliyyah of Science, IIUM Kuantan. The aquaponics system was filled

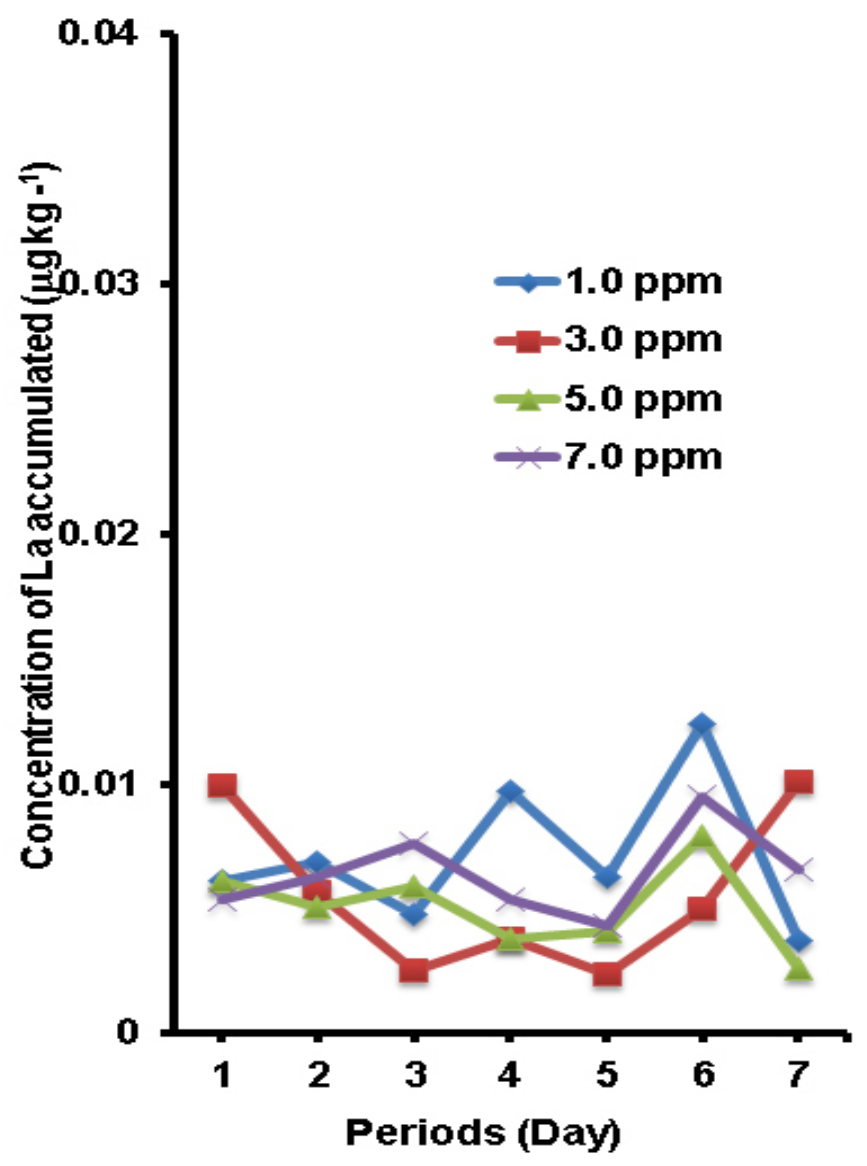

Fig. 2: Concentration of La accumulated by leaf section of P. stratiotes for all treatments 
with artificial wastewater effluents containing REE. REE standards with known concentration in ppm were prepared and mixed in the aquaponics system. The plant was given a liquid hydroponic fertilizer that was free from REE and radioactive residues.

\section{Sample preparation}

After cultivation in the aquaponics system, the plants were harvested every day for up to one week. The plant samples were separated into root and leaf parts. The samples were dried at $60{ }^{\circ} \mathrm{C}$ for $48 \mathrm{~h}$ using a vacuum oven and later ground into powder form using a blender before being stored prior to further analysis.

\section{Chemical analysis Reagents}

All reagents were of analytical reagent grade. Ultra-pure water was used for all dilutions. The REE standard solutions (1.0, 3.0, 5.0 and 7.0 ppm) for the calibration were prepared by diluting stock solutions of $100 \mathrm{ug} \mathrm{mL}-1$ levels.

\section{Analysis of artificial wastewater sample}

Concentrated $\mathrm{HNO}_{3}(9 \mathrm{~mL})$ was added to filtered wastewater sample and heated gently at $70{ }^{\circ} \mathrm{C}$ until the solution became transparent ${ }^{17}$. The solutions were allowed to cool and filtered using 0.45 ìm membrane filters. The solutions were then added up with ultra-pure water to $100 \mathrm{~mL}$ and kept at room temperature prior to ICP-MS analysis.

\section{Analysis of water lettuce plant sample}

All the glassware and plastics were soaked overnight in $10 \%(\mathrm{v} / \mathrm{v})$ nitric acid, rinsed with distilled water and deionized water, and dried prior to analysis. Five (5) gram of aquatic plant parts were digested with a strong acid digestion $\left(\mathrm{H}_{2} \mathrm{O}_{2}\right.$ and conc. $\mathrm{HNO}_{3}$ ) mixture at $1: 3$ ratios at $150{ }^{\circ} \mathrm{C}$ for $20 \mathrm{~min}$ and allowed to cool at room temperature. Samples were diluted to $50 \mathrm{~mL}$ volume with ultra-pure water, filtered through 0.45 ìm membrane filter and kept at room temperature prior to ICP-MS analysis.

\section{Rare earth elemental analysis by ICP-MS}

All samples were determined using inductively coupled plasma mass spectrometry (ICP-MS, Perkin Elmer, USA). External calibration was performed by measuring standard solutions containing lanthanum chloride at 1, 5, 10, 20, 50 and $100 \mathrm{mg} \mathrm{L}^{-1}$ concentrations. REEs calibration solutions were prepared by diluting stock solutions of $100 \mu \mathrm{g} \mathrm{L}^{-1}$ of each element. The calibration curve for quantitative analysis of REE was established. The concentrations of REEs were presented in $\mathrm{g} \mathrm{kg}^{-1}$, wet weight for plant samples and $\mu \mathrm{g} \mathrm{L}^{-1}$ for water.

\section{Statistical analysis}

Statistical analysis was carried out using SPSS v20. All the analyses of REE content in aquatic plant samples were performed in triplicate. The results obtained were analyzed by one-way ANOVA using SPSS for Windows version 20.0. Where effects were significant, differences between the means were analyzed using Tukey's test for multiple comparisons of means.

\section{RESULTS AND DISCUSSION}

\section{Lanthanum (La) accumulation at root and leaf sections}

In order to identify the effectiveness of $P$. stratiotes in removing rare earth metals, after 7 days of treatment, bioaccumulation of the lanthanum (La) in $P$. stratiotes was observed by examining the root and leaf samples collected from the treatment tanks and analysed using ICP-MS.

Based on Figure 1,P. stratiotes exposed to treatments of $1.0,3.0,5.0$ and $7.0 \mathrm{ppm}$ showed accumulation of $\mathrm{La}$ at the root section on the $1^{\text {st }}$ until $7^{\text {th }}$ day of exposure. It was found that on the $1^{\text {st }}$ day, the accumulated La was significantly higher $(p<0.05)$ in the root exposed to $1.0 \mathrm{ppm}$ than other concentrations (5 and $7 \mathrm{ppm}$ ). The accumulation of La increased on the $2^{\text {nd }}$ day but began to fluctuate through the $3^{\text {rd }}$ day until $7^{\text {th }}$ day of exposure. The increases of La contents on the $2^{\text {nd }}$ day were significantly different $(p<0.05)$ as compared to the $1^{\text {st }}$ day of exposure when the roots were treated with 1.0, 3.0 and 7.0 ppm respectively. However, the accumulation of $\mathrm{La}$ in the root section when treated with 5.0 ppm was not significantly different ( $p>0.05)$. The accumulation of La in the root of $P$. stratiotes was higher on the $2^{\text {nd }}$ day might be due to the enhancement of the cell membrane permeability, thus allowing further accumulation of $\mathrm{La}^{18}$. Meanwhile, on the $3^{\text {rd }}$ day, the La concentrations were significantly decreased $(p>0.05)$ in all treatments $(1.0,3.0,5.0$ and $7.0 \mathrm{ppm})$. The reduction in La accumulation 


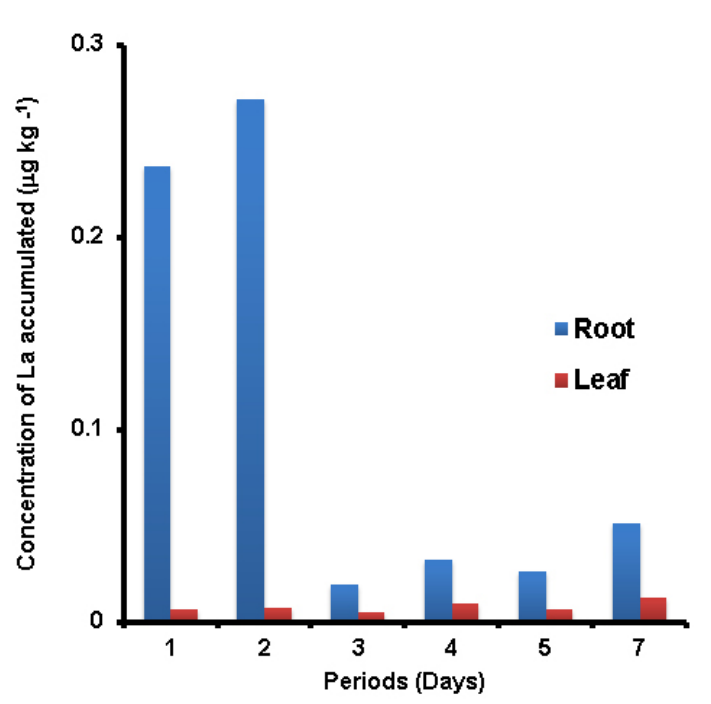

Fig. 3: Concentration of La accumulated at root and leaf section at $1 \mathrm{ppm}$ treatment of $\mathrm{LaCl}_{3}$

on the $3^{\text {rd }}$ day might be due to plant's strategy in tolerating the amount of metals entering the plant sections ${ }^{19}$. The result indicates that $P$. stratiotes exposed to a higher concentration treatment showed a lower metal accumulation compared to $P$. stratiotes that was exposed to a lower concentration treatment (Fig. 1). It was also found that the exposure for a longer time (more than 2 days) might have caused saturation in the root cells, preventing further take up of $\mathrm{La}^{20}$. Different plants might have different accumulation capacities. P. stratiotes was reported to have larger $\mathrm{Hg}$ uptake and accumulation compared to water hyacinth (Eichornia crassipes) ${ }^{21}$.

Figure 2 showed that the concentration of $L a$ accumulated in the leaf section of $P$. stratiotes. It was found that on the $1^{\text {st }}$ and $7^{\text {th }}$ day of exposures, the La content in the leaf section were significantly higher $(p<0.05)$ when the plant was treated with 3.00 ppm as compared to other treatments (1.0, 5.0 and $7.0 \mathrm{ppm}$ ). Meanwhile, the accumulations of La were statistically higher on the $4^{\text {th }}$ and $6^{\text {th }}$ day of exposures when the plant was treated at low concentration (1.0 $\mathrm{ppm}$ ) as compared to other treatments (3.0, 5.0 and $7.0 \mathrm{ppm}$ ). Previous studies have shown that the accumulation of metals occur not only at the root area but also up to the leaves of plants. Odjegba and Fasidi $^{22}$ studied the accumulation of trace elements in $P$. stratiotes and supported this finding.

\section{Comparison of La accumulation between root and leaf section}

Figure 3 shows the La accumulated in the root and leaf section when the plant was treated with $1.0 \mathrm{ppm}$. The accumulation of $\mathrm{La}$ in root was significantly higher than in the leaf section. On the $1^{\text {st }}$ day, with treatment of $1 \mathrm{ppm}$ the La accumulated at the root section was 38 times greater than La accumulated at the leaf section, respectively. The highest concentration of lanthanum was found in the root section $\left(0.272 \mathrm{\mu g} \mathrm{kg}^{-1}\right)$ on the $2^{\text {nd }}$ day compared to the leaf section $\left(0.0124 \mu \mathrm{g} \mathrm{kg}^{-1}\right)$ on the $6^{\text {th }}$ day, when both parts were treated with $1.0 \mathrm{ppm}$. A study conducted by Dahmani-Mueller et al. ${ }^{23}$ showed that there are plant species that accumulate more metal in the root section compared to the leaf section and vice versa. This indicates that the uptake of La occurs up to the leaf section of $P$. stratiotes although its concentration is significantly low. Plants have a highly organised mechanism to acquire nutrients or take up low concentration levels of contaminants from the environment ${ }^{24}$. Mechanisms like transpirational pull and the presence of the Casparian strip play an important part in the uptake of minerals or contaminants into root cells. The apoplastic pathway allows water and mineral to pass through the cell walls of the root cortex whereas the symplastic pathway, which uses plasmodesmata located between neighbouring cell walls and enables the substances to be taken to xylem.

\section{CONCLUSION}

In conclusion, this study shows that $P$. stratiotes can accumulate $\mathrm{La}$ at its root and leaf sections. This indicates that this aquatic plant can be a potential bioaccumulation agent to remediate environmental contaminations from La. The root section accumulated higher La concentrations compared to the leaf section. The transport system of plants and metal uptake ability of $P$. stratiotes allow for the bioaccumulation of La in these plant sections. Low levels of La can be accumulated by P. stratiotes, thus making this plant a potential phytoremediation plant for treating La metal contaminations at very low concentrations. 


\section{REFERENCES}

1. Brioschi, L.; Steinmann, M.; Lucot, E.; Pierret, M. C.; Stille, P.; Prunier, J.; Badot, P. M. Plant Soil 2013, 366, 143-163.

2. Humphries, M. CRS Report for Congress: Rare Earth Elements. 2013, Bibliogov Publisher, United States.

3. Zhang, C.; Li, Q.; Zhang, M.; Zhang, N.; Li, M. Acta Pharm. Sin. B, 2013, 3, 20-24.

4. Australian Mining. Lynas wins full operating licence for its LAMP, 2014 retrieved at https:// australianmining.com.au/news/lynas-winsfull-operating-licence-for-its-lamp-2/ retrieved on 24 April 2016.

5. Al-Areqi, W. M.; Majid, A. A.; Sarmani, S. Malaysian Journal of Analytical Sciences 2014, 18, 221-225.

6. Mayfield, D. B.; Fairbrother, A. Chemosphere 2015, 120, 68-74

7. AELB. Clarification by AELB on the removal of Lynas residue. Press statement by Executive secretary, Atomic Energy Licensing Board (MOSTI), Malaysia

8. Razak, A. S.; Wahid, Z.; Zakaria, I.; Mohd Said, M. I.; Sulaiman, S.; Halim, H. 2013. Adv. Environ. Biol. 2013, 7, 3802-3807.

9. Eneji, I. S.; Sha'ato, R.; Annune, P. A. (2011). Pak. J. Anal. Environ. Chem. 2011, 12, 1-2

10. Low, K. H.; Zain, S. M.; Abas, M. Ft.; Salleh, K. M.; Teo, Y. T. Food Chem. 2015, 177, 390396.

11. Baharom, Z. S.; Ishak, M.Y. Procedia Environ.
Sci. 2015, 30, 320-325.

12. Singh, D.; Tiwari, A.; Gupta, R. J. Agric. Tech. 2012, 8, 1-11.

13. Emmanuel, E. S. C.; Anandkumar, B.; Natesan, M.; Maruthamuthu, S. Aust. J. Crop Sci. 2010, 4, 289-294.

14. Hong, F.; Wang, L.; Meng, X. Biol. Trace Elem. Res. 2002, 89, 263-276.

15. Li, X.; Chen, Z.; Chen, Z.; Zhang, Y. Chemosphere 2013, 93, 1240-1246.

16. 11th Malaysia Plan. Anchoring Growth on People. Strategy B5. Managing waste holistically 2014, page 145

18. Chang, J. Plant Physiol. Comm. 1991, 27, 17-21

19. Taylor, S. R.; McLennan, S. M. The continental crust: its composition and evolution. Blackwell Scientific Publication, Carlton 1985, p. 312

20. Das, S.; Goswami, S.; Talukdar, A. D. Bull. Environ. Contam. Toxicol. 2014, 92, 169174.

21. Skinner, K.; Wright, N.; Porter-Goff, E. Environ. Pollut., 2007, 145, 234-237.

22. Odjegba, V. J.; Fasidi, I. O. Ecotoxicol. 2004, 13, 637-646.

23. Dahmani-Muller, H.; Van Oort, F., Gelie, B.; Balabane, M. Environ. Pollut. 2000, 109, 231-238.

24. Tangahu, B. V.; Sheikh Abdullah, S. R.; Basri, H.; Idris, M.; Anuar, N.; Mukhlisin. M. Int. J. Chem. Eng. Vol. 2011, Article ID 939161, 31 pages 